\title{
The Influence of Toll-Like Receptor Stimulation on Expression of EBV Lytic Genes
}

\author{
JOANNA SIENNICKA*, AGNIESZKA TRZCIŃSKA, AGNIESZKA CZĘŚCIK, \\ MILENA DUNAL-SZCZEPANIAK and BARBARA ŁAGOSZ
}

\author{
Department of Virology, National Institute of Public Health - National Institute of Hygiene, Warsaw, Poland
}

Submitted 24 September 2012, revised 7 December 2012, accepted 17 April 2013

\author{
Abstract
}

\begin{abstract}
Epstein-Barr virus (EBV) establishes latency in the resting memory B-cell compartment. It has been recently suggested that maintenance of chronic infection is dependent on periodic reactivation. Although the stimuli for EBV reactivation in vivo during natural infections are largely unknown, there is evidence indicating that heterologous infections could trigger herpesviruses reactivation. The purpose of this work was to identify the influence of Toll-like receptors stimulation on EBV replication in EBV latently infected Burkitt lymphoma cells (P3HR-1, Raji and Namalwa). The cells were stimulated with Pam3CSK4 (synthetic triacylated lipoprotein), PolyI:C (synthetic analog of dsRNA), LPS (lipopolysaccharide from E.coli), measles virus (MeV) and PMA (phorbol myristate acetate). Non-stimulated cells (NS) served as control. EBV expression was investigated at mRNA level for three viral lytic genes: BZLF1 (immediate early, ZEBRA), BALF2 (early, EA) and BcLF1 (late, VCA). Additionally, the effect of stimulation on NF-kBp65 and inflammatory cytokines (IL-1b, IL-6, IL-8, IL-10, IL-12p70, and TNF) was investigated. Stimulation of TLRs led to limited changes in EBV expression manifesting as increase of ZEBRA at mRNA level in cells treated with PolyI:C and Pam3CSK4. Stimulation with PolyI:C, Pam3CSK4 and LPS also lead to considerable increase of NF-kBp65, while increased levels of inflammatory cytokines were observed for IL-8, TNF and IL-6 in cells treated with PMA and MeV. In conclusion, the results of our experiments support the suggestion that TLRs stimulation with microbial ligands influences EBV virus replication.
\end{abstract}

Ke y wo r ds: Burkitt lymphoma cells, Epstein-Barr virus, lytic genes expression

\section{Introduction}

Epstein-Barr virus (EBV) is characterized by a capacity to establish lifelong latent infection of both $B$ type and epithelial cells. It has been documented that more than $95 \%$ of human beings worldwide are persistently infected with EBV. Epstein-Barr virus is the etiological agent of different diseases. Primary infection, occurring usually during early childhood is mainly asymptomatic or results in infectious mononucleosis. In rare cases EBV, as a potent growth-transforming factor, could be a cause of various malignancies, including Burkitt lymphoma (Rickinson and Kieff, 2007). The EBV genome includes more than 70 open reading frames that enable the transcription of genes for several different proteins. Different forms of infections (lytic or latent) are characterized by expression of distinct combinations of these proteins. While in lytic infection the whole complex of immediate early, early, and late lytic cycle proteins is expressed, in latent infection the limited expression of latent genes occurres. Different forms of latency have been recognized. Latency 0 ,
I and II infections are characterized by expression of a very limited set of EBV proteins (e.g. only EBNA 1 in latency I), while in latency III infection a large pattern (at least 10 proteins and 2 RNAs) is presented (Thompson and Kurzrock, 2004; Rowe et al., 2009; Kieff and Rickinson, 2007). In Burkitt lymphoma cell (BL) the latency pattern I has been documented.

Continuous cell lines derived from BL made possible to carry out studies on both carcinogenesis and viral latency-associated processes. The lines commonly used for these studies are Raji, P3HR-1 and Namalwa. All of these B-type, lymphoid cell lines maintain EBV genomes, however in each of them EBV genome represents distinct properties. EBV DNA present in Raji in form of free extrachromosomal DNA plasmids has a deletion in the BALF2 gene, which restricts the virus replication to the early phase and causes complete inhibition of viral DNA synthesis (Decausin et al., 1995). P3HR-1 cells exhibit a single deletion, which does not limit viral replication, while Namalwa cell-line carries about 50 viral copies integrated into the host genome and is EBV non-productive (Bernasconi et al., 2006).

\footnotetext{
* Corresponding author: J. Siennicka, Department of Virology, National Institute of Public Heath - National Institute of Hygiene, Chocimska 24, 00-791 Warsaw, Poland; phone: +48 22 5421230; e-mail address: jsiennicka@pzh.gov.pl
} 
EBV establishes latency in the resting memory B-cell compartment. It has been recently suggested that the maintenance of chronic infection depends on periodic reactivation (Coleman et al., 2010; Vogl et al., 2012). Although the stimuli for EBV reactivation during natural infections in vivo are largely unknown, there is evidence indicating that heterologous infections could trigger virus reactivation (Varthakavi et al., 1999; Arcenas and Widen, 2002; Merat et al., 2002; Shimozuma et al., 2010). In in vitro experiments, agents such as phorbol 12-myristate 13-acetate (PMA), also known as 12-O-tetradecanoyl phorbol-13-acetate (TPA), sodium butyrate and calcium ionophores are commonly used to induce the lytic form of EBV infection (Kenney, 2007; Adler et al., 2002). PMA is a specific activator of protein kinase $C$ and hence of nuclear factor kappa $B$ $(\mathrm{NF}-\mathrm{kB})$. NF-kB regulates the expression of a wide variety of genes including these playing a critical role in immune response, but it is also known that activation of NF-kB occurs by Toll-like receptors (TLRs) induction (Moynagh, 2005).

TLRs are important components of the host innate recognition system. TLRs have the ability to recognize highly conserved structures specific to microbial pathogens - PAMPs (Pathogen-Associated Molecular Patterns) (Pasare and Medzhitov, 2004). In total, 13 mammalian TLRs (11 being expressed in humans) are known, and each TLR has its own specific ligands. TLR2, for example, recognizes the greatest variety of ligands among all TLRs, such as peptidoglycan, lipoteichoic acid and lipoprotein from Gram-positive bacteria, but also proteins of viruses such as measles virus (MeV), cytomegalovirus (CMV) and Herpes simplex virus (HSV). TLR4 recognizes lipopolysaccharide (LPS) - compounds unique for Gram-negative bacteria but also viral proteins such as envelope protein of mouse mammary tumor virus (MMTV) or fusion protein of respiratory syncytial virus (RSV). TLR3 recognizes RNA from double-stranded and negative-sense RNA viruses (Finberg and Kurt-Jones, 2004; Pasare and Medzhitov, 2004; Hopkins and Sriskandan 2005). Except for their fundamental role as innate immunity components, it appears that TLRs also take part in the generation of clonal adaptive immune response, noninfectious disease pathogenesis and maintenance of homeostasis (Hopkins and Sriskandan, 2005).

In B lymphocytes mRNA for most TLRs is expressed. Activation of these receptors by ligands leads to various responses: proliferation, differentiation into antibodysecreting cells, more efficient antigen presentation or cytokine secretion. This means that B lymphocytes as one of the major lymphocyte population in secondary lymphoid tissues (up to 50\% of cells) are stimulated in response to the wide spectrum of antigens which influence immune activation in the vicinity (Gray et al.,
2007). Since the Epstein-Barr virus establishes latency in B cells, the purpose of this work was to study if TLR stimulation could trigger EBV replication in latently EBV-infected Burkitt lymphoma cells.

\section{Experimental}

Materials and Methods

Cells. P3HR-1, Raji and Namalwa cells obtained from ATCC were maintained in RPMI 1640 medium (Roswell Park Memorial Institute) supplemented with $10 \%$ fetal bovine serum obtained from Sigma-Aldrich (St. Louis, USA) and antibiotics (penicillin and streptomycin) obtained from Polfa-Tarchomin (Warsaw, Poland) as suspension cultures at $37^{\circ} \mathrm{C}$ and $5 \% \mathrm{CO}_{2}$.

Ligands. The cells at $3 \times 10^{5} / \mathrm{ml}$ concentration were stimulated ( $24 \mathrm{~h}$ ) with $1 \mu \mathrm{g} / \mathrm{ml}$ Pam3CSK4 (synthetic triacylated lipoprotein) as the TLR2 ligand, $25 \mu \mathrm{g} / \mathrm{ml}$ PolyI:C (synthetic analog of dsRNA) as the TLR3 ligand, $10 \mu \mathrm{g} / \mathrm{ml}$ Escherichia coli LPS as the TLR4 ligand, measles virus (MeV, Schwarz strain) at MOI (the multiplicity of infection) of 0.002 and $0.5 \mu \mathrm{g} / \mathrm{ml}$ PMA (phorbol myristate acetate). Non-stimulated cells (NS) served as control. Ligands were obtained from InvivoGen (San Diego, USA).

EBV lytic genes expression at mRNA level. EBV genes expression was investigated using nested RTPCR with mRNA obtained from stimulated and nonstimulated cells using Oligotex Direct mRNA Mini Kit (Qiagen, Hilden, Germany). Expression lytic transcripts of EBV encoded by BZLF1 (immediate early, ZEBRA), BALF2 (early, EA) and BcLF1 (late, VCA) genes was evaluated by nested RT-PCR according to the Bergallo et al. (2007) procedure with slight modifications. Amplification was performed separately for each transcript using OneStep RT-PCR kit (Qiagen, Hilden, Germany). The first-round was carried out using the outer primers pairs (Genomed, Warsaw, Poland) with a final concentration of $0.6 \mu \mathrm{M}$. The volume of the added sample was $1 \mu \mathrm{l}$ with a final reaction volume $25 \mu \mathrm{l}$. After reverse transcription $\left(30 \mathrm{~min}\right.$ at $\left.50^{\circ} \mathrm{C}\right)$ and initial denaturation step of $15 \mathrm{~min}$ at $95^{\circ} \mathrm{C}$, the amplification was carried out under the following conditions: $94^{\circ} \mathrm{C}$ for $30 \mathrm{sec}, 62^{\circ} \mathrm{C}$ for $30 \mathrm{sec}, 72^{\circ} \mathrm{C}$ for $90 \mathrm{sec}$ for $30 \mathrm{cycles}$ and then $5 \mathrm{~min}$ at $72^{\circ} \mathrm{C}$. The second-round was carried out with internal primers pairs (final concentration $0.6 \mu \mathrm{M}$ ) using a set of OneStep RT-PCR with the modification of replacing the Enzyme Mix with AmpliTaqGold DNA polymerase (Applied Biosystems, Carlsbad, USA) with a final concentration of $0.06 \mathrm{U} / \mu \mathrm{l}$. Amount of sample added was the same as in the first-round. Amplification conditions were following: $15 \mathrm{~min}$ at $95^{\circ} \mathrm{C}$; 25 cycles: $94^{\circ} \mathrm{C}$ for $30 \mathrm{sek}, 57^{\circ} \mathrm{C}$ for $30 \mathrm{sek}, 72^{\circ} \mathrm{C}$ for $1 \mathrm{~min}$ and then 
$5 \mathrm{~min}$ at $72^{\circ} \mathrm{C}$. The three second-round PCR products (567 bp, BZLF1; 117 bp, BALF2; 181 bp, BcLF1) were analyzed using electrophoretic separation. Electrophoretic separation was made in $2 \%$ agarose gel stained with GelRed (Biotium, Hayward, USA). Band intensity was determined using tools for quantitative analysis available with Gel DocTMXR and Quantity One 4.4 software (Bio-Rad, Hercules, USA) and expressed as volume intensity per $\mathrm{mm}^{2}$ (INT). EBV genes expression was normalized to the expression of glyceraldehyde-3-phosphate dehydrogenase (GAPDH) gene that was detected according to the procedure developed by Bergallo et al. (2007), and described in an earlier publication (Siennicka et al., 2011). The criterion for assessing the experiment was stimulation-induced shift of EBV genes expression measured by $25 \%$ change of band intensity compared to that of non-stimulated control. The value of $25 \%$ was calculated taking into account the mean and the standard deviation of the GAPDH band intensity. The assessment value was greater than three standard deviation value of band intensity obtained as a result of GAPDH gene amplification.

NF-kBp65 level. The level of transcription factor NF-kBp65 was determined in stimulated and control cells. Nucleic acid-binding protein fraction was isolated using Qproteome ${ }^{\mathrm{TM}}$ Nuclear Protein kit (Qiagen, Hilden, Germany) and then was tested using EZ-TFA Transcription Factor Assay - Colorimetric (Millipore, Tenecula, USA) based on enzyme-linked immunosorbent assay analysis. The amount of NF-kB subunit p65 was expressed as OD value at $450 \mathrm{~nm}$ obtained for NF-kB after subtraction of OD value obtained for negative control.

Cytokines. Cytokines were determined in supernatants from stimulated and control cells. The quantitative measurement of IL-1b, IL-6, IL-8, IL-10, IL12 p70, and TNF was performed by flow cytometry with Cytometric Bead Array technique (CBA Human Inflammatory Cytokines Kit, Becton-Dickinson, USA). CBA technique combines the principles of the sandwich immunoassay with the capability of flow cytometry and allows for simultaneous determination of six cytokines concentration in a single sample. The analysis of CBA data was performed using FCAP Array software v1.0.1 (Becton-Dickinson, San Jose, USA) which allows to optimize reading analyzed concentrations expressed as $\mathrm{pg} / \mathrm{ml}$ from ten-points standard curve.

\section{Results}

GAPDH expression. The influence of stimulation on housekeeping (GAPDH) gene expression was evaluated. The level of expression was expressed as band intensity (volume intensity per $\mathrm{mm}^{2}$; INT). In NS control GAPDH expression level (INT) was similar in all cell types: 92, 92 and 98 for P3HR-1, Namalwa and Raji respectively. The stimulation does not change the housekeeping gene expression. The average level of GAPDH mRNA (INT) in stimulated and NS cells was: $78.67 \pm 8.7$ for P3HR-1, $87.67 \pm 6.4$ for Namalwa and $90.00 \pm 5.2$ for Raji. The average level of GAPDH mRNA is shown in Fig. 1.

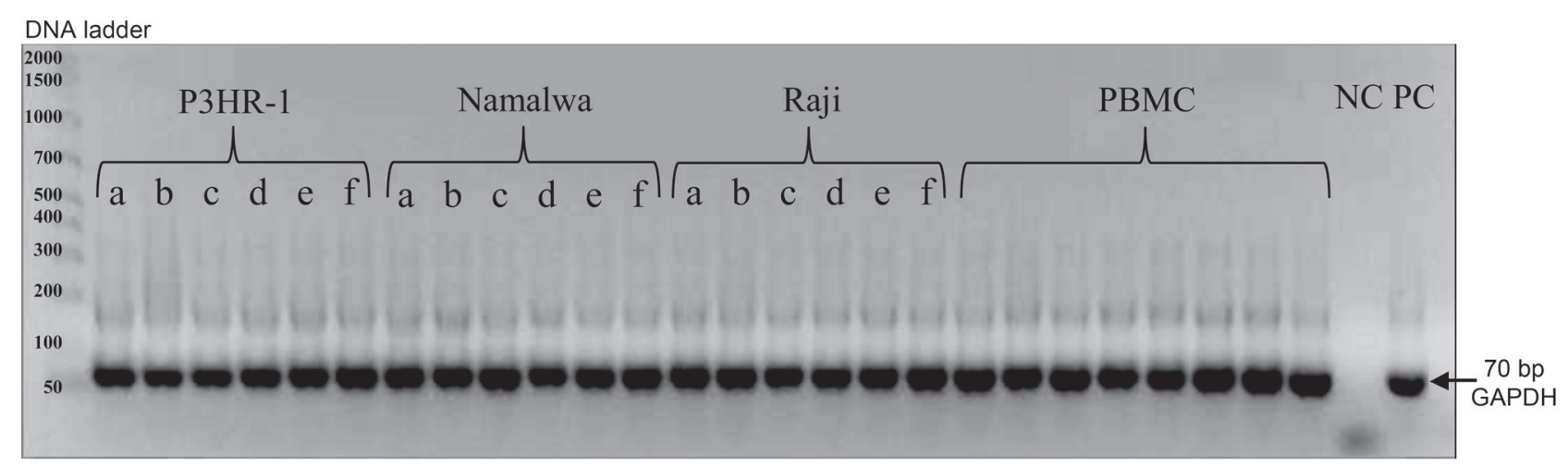

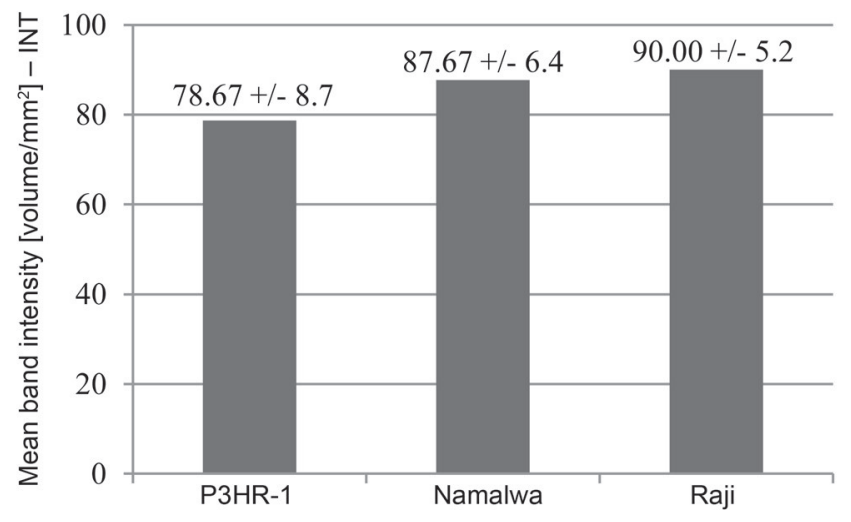

Fig. 1. Expression of GAPDH gene in Burkitt lymphoma (BL) cells.

Electrophoretic gel with RT-PCR products obtained from BL cells stimulated with: Pam3CSK4 (a), PolyI:C (b), LPS (c), PMA (d), MeV (e) and non-stimulated (f) and from PBMC of healthy individuals. NC, PC - negative and positive PCR control.

Graph represents mean band intensity determined with Quantity One 4.4 software (Bio-Rad) for stimulated and NS cells. 


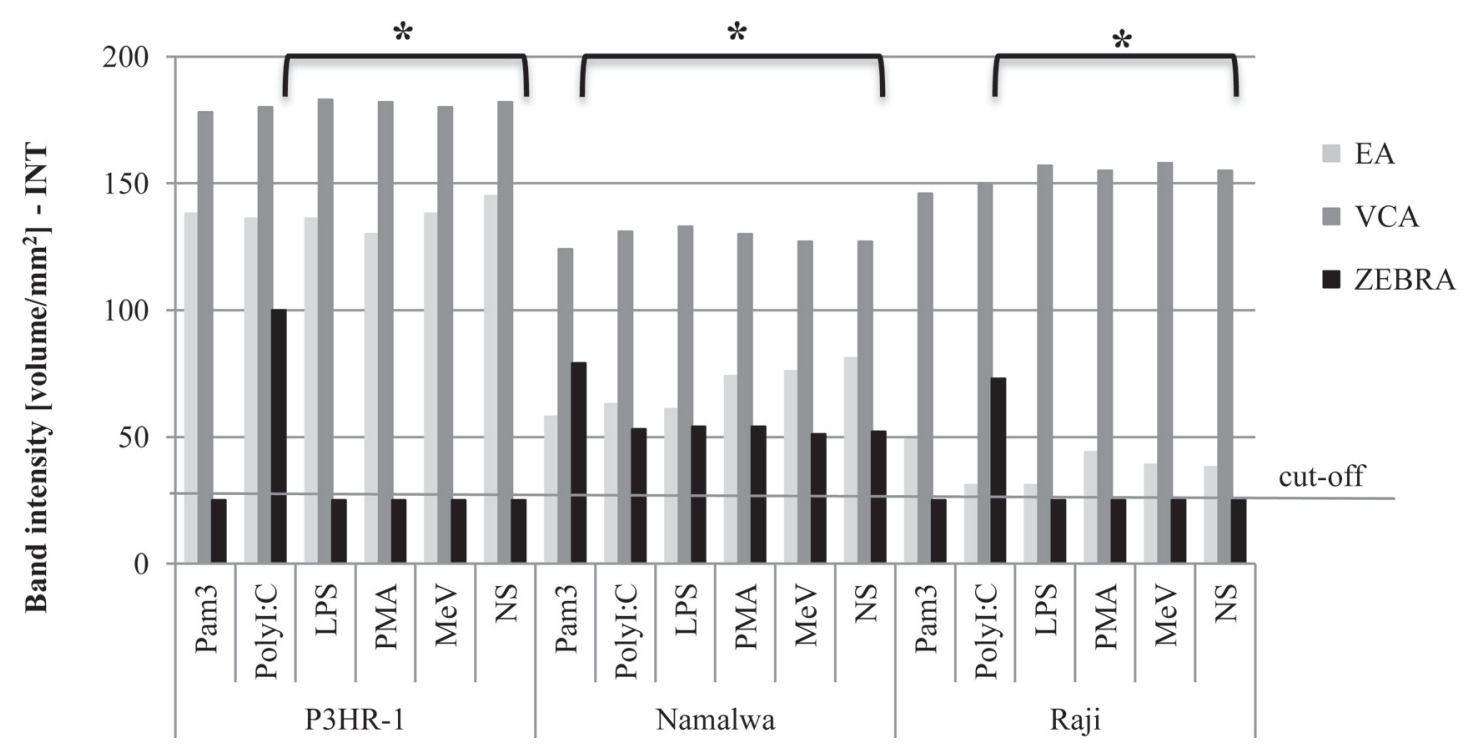

Fig. 2. Expression of EBV lytic genes (EA, VCA, ZEBRA) in BL cells.

Cut-off refers positive (above) and negative (below) PCR results.

* Increase in the intensity of band by $25 \%$ compared to non-stimulated (NS) control.

EBV lytic genes expression. The following patterns of expression of tested genes were observed in control NS cells: EA (+), VCA (+), ZEBRA (-) for Raji, EA (+), VCA (+), ZEBRA (+) for Namalwa and EA (+), VCA $(+)$, ZEBRA (-) for P3HR-1. In comparison to NS control the stimulation led to few changes. In all cell lines these changes were related only to increase of ZEBRA gene expression: in P3HR-1 from 25 INT to 100 INT after PolyI:C stimulation; in Raji from 25 INT to 75 INT after PolyI:C stimulation and in Namalwa from 52 INT to 79 INT after Pam3CSK4 stimulation (Fig. 2).

NF-kBp65 level. Stimulation with TLRs ligands lead to considerable increase of NF-kBp65 concentration, that was approximately two-fold higher in comparison to NS control but was detected only in P3HR-1 and Namalwa cells after induction with Pam3CSK4, PolyI:C and LPS (Fig. 3). In non-stimulated cells the highest level of NF-kBp65 was observed in Raji (OD 0.273). This level was 2.3 fold higher than in Namalwa (OD 0.117) and 2.0 fold higher than in P3HR-1 (OD 0.138). Stimulation with PMA do not lead to increase of NF-kBp65 concentration.

Cytokines levels. The marked differences in cytokine production were observed. These differences were dependent on both - the type of cells as well as the stimulator. For all cell lines tested the highest levels of IL-8, TNF and IL-6 were observed after stimulation with phorbol (PMA) and $\mathrm{MeV}$ virus (Fig. 4). The

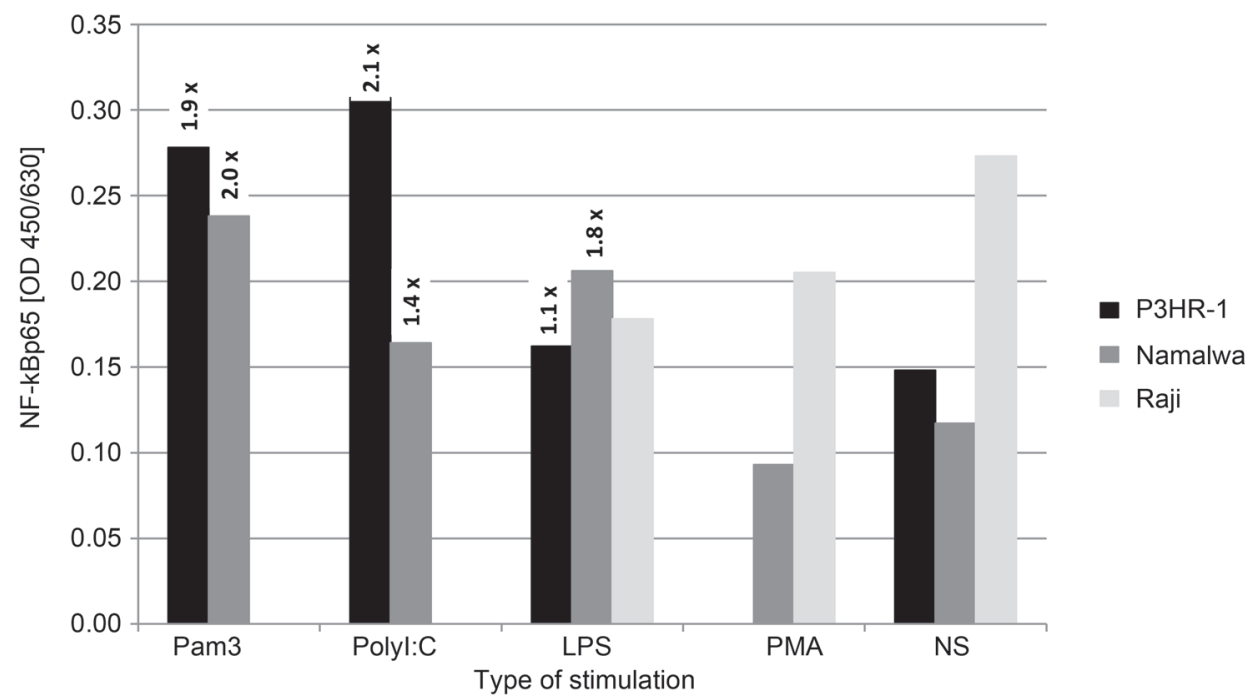

Fig. 3. Determination of NF-kBp65 level in Burkitt lymphoma cells after induction with TLRs ligands (Pam3CSK4, PolyI:C, LPS) and PMA.

The increase rate of NF-kBp65 level in comparison to NS control (non-stimulated cells) indicated as an index above the bars. 

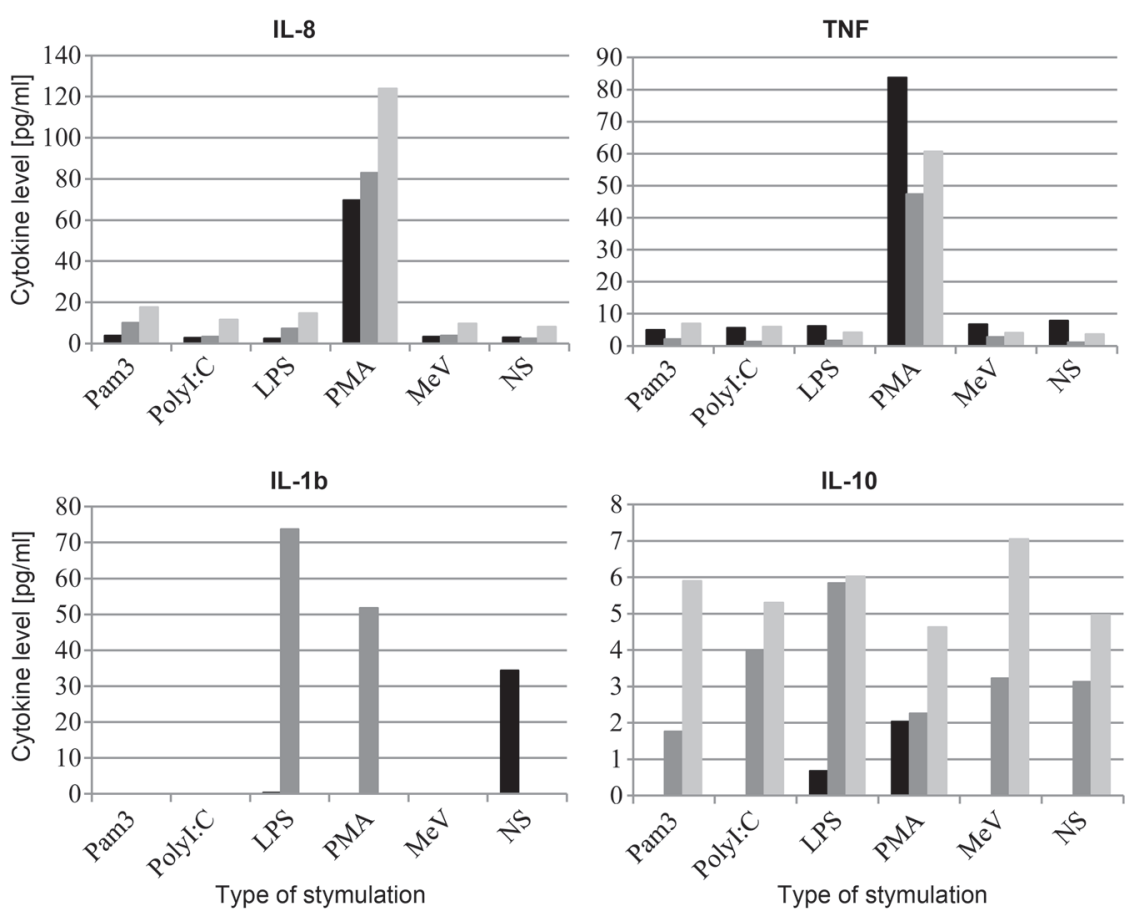

IL-10

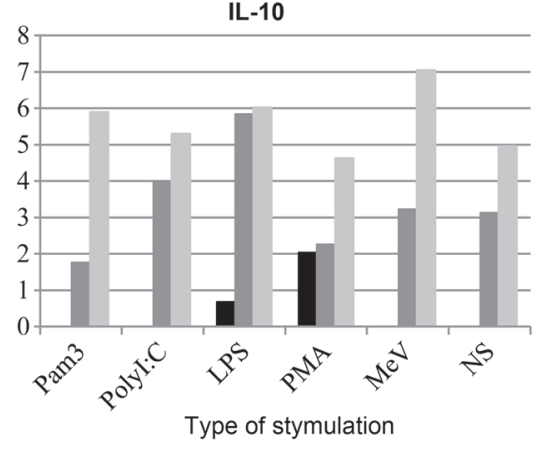

P3HR-1

- Namalwa

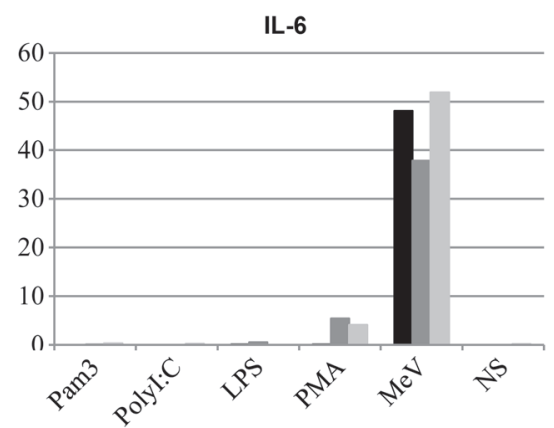

IL-12p70

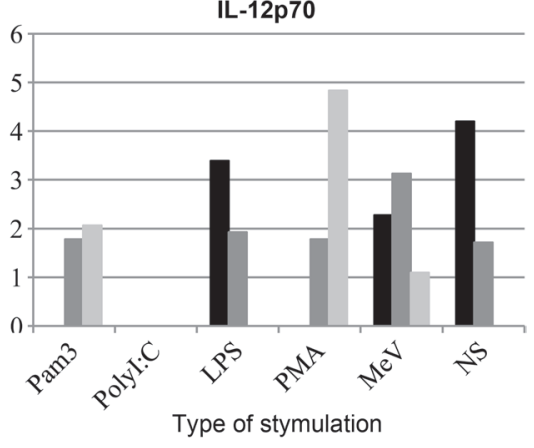

Raji

Fig. 4. The level of cytokines measured in supernatants after BL cells stimulation.

Limits of detection defined by producer were: $1.9 \mathrm{pg} / \mathrm{ml}$ for IL-12p70, $2.5 \mathrm{pg} / \mathrm{ml}$ for IL-6, 3.3 pg/ml for IL-10, $3.6 \mathrm{pg} / \mathrm{ml}$ for IL-8, $3.7 \mathrm{pg} / \mathrm{ml}$ for TNF and $7.2 \mathrm{pg} / \mathrm{ml}$ for IL-1b.

increase of IL-1b was observed after stimulation with LPS and PMA but only in Namalwa cells. The levels of IL-10 and IL-12p70 were only slightly higher than the detection level (LOD levels are given in Fig. 4 footnote).

\section{Discussion}

Stimulation of Toll-like receptors by PAMPs leads to the activation of intracellular signaling pathways resulting in nuclear factor NF-kB activation and secretion of cytokines (Finberg and Kurt-Jones, 2004; Hopkins and Sriskandan, 2005). Burkitt lymphoma cells, as a line deriving from B-cell lineage express most of TLRs, however according to Henault et al. (2005) Namalwa cells express mainly TLR9 and TLR7 but not TLR2, TLR3, and TLR8. Recent data show that TLR stimulation can drive reactivation of herpes virus from latency. Gargano etal. (2009) described the ability of TLR ligands to induce ex vivo as well as in vivo reactivation of gamma herpesvirus MHV68 in latently infected mouse. TLRs induced signaling in response to herpesvirus-unrelated infections leads to B-cell activation, their proliferation and EBV virus reactivation. It was also assumed that periodic exposure to the pathogen may contribute to homeostatic maintenance of chronic gamma herpesvirus infection through stimulating virus reactivation and reseeding reservoirs of latency (Gargano et al., 2009). This is consistent with the results of Coleman et al. (2010) who examined the possibility of gamma herpesviruses to utilize the self-renewing reservoir of developing B-cells to maintain lifelong infection in the circulating mature B-cell compartment. Iskra et al. (2010) examined in what way TLRs stimulation influence EBV-driven proliferation in human B-cells and concluded that proliferation of EBV infected B-cells may be directly influenced by microbial compounds present at the site of infection via TLRs stimulation.

In the presented experiments stimulation of TLRs led to limited changes in EBV expression emerging as the increase of ZEBRA mRNA level. ZEBRA (BZFL1) is a site specific DNA binding protein that functions as a transcriptional activator. It is assumed that enhanced binding of ZEBRA to oriLyt is crucial for lytic viral DNA replication (El-Guindy et al., 2010). Taking into account the role of ZEBRA gene in the process of EBV reactivation our observation that TLRs stimulation influences the expression EBV genes by transcription of this activator is of great importance.

Some aspects of this experiment remain unsolved. The main question is why did stimulation with PMA, that is known as a strong reactivation agent, does not exert the expression of EBV lytic genes, while Pam3CSK4 and PolyI:C did. It should be pointed out that these two ligands also increased the level of NF-kB, while PMA did not. On the other hand, stimulation with PMA caused a considerable increase of inflammatory cytokines; IL-8 and TNF, known as the contributors 
in reactivation process (Hummel and Abecassis, 2002). Interestingly, stimulation with measles virus $(\mathrm{MeV})$ - known as TLR2, TLR4 and TLR3 activator - triggered significant increase of IL-6, but not of IL-8 or TNF. Unfortunately, we did not inspect the influence of $\mathrm{MeV}$ stimulation on $\mathrm{NF}-\mathrm{kB}$ expression. It would be interesting to know if viral RNA exerts the same impact on NF-kB level as PolyI:C the synthetic analog of dsRNA recognized by TLR3.

The limitation of the study could be the method used for evaluation of gene expression. In fact densitometry is not the most precise method to measure the changes in gene expression. To ensure that TLRs stimulation influences EBV genes expression, very restrictive conditions have been applied. The other limitation is conducting experiments without replication. This made impossible to carry out statistical analyses. Conducting a wide-planned experiment (the strength of this study) allows to make valuable observations, that however should be confirmed in future studies.

In conclusion, the results of our experiments support the suggestion that TLRs stimulation with microbial ligands influences EBV virus replication.

\section{Acknowledgments}

We thank Elżbieta Gaińska and Gideon Rosenberg for editorial assistance. This research was supported by Polish Ministry of Science and Higher Education (grant NN 404 002337).

\section{Literature}

Adler B., E. Schaadt, B. Kempkes, U. Zimber-Strobl, B. Baier and G.W. Bornkamm. 2002. Control of Epstein-Barr virus reactivation by activated CD40 and viral latent membrane protein 1. Proc. Natl. Acad. Sci. USA 99: 437-442.

Arcenas R. and R.H. Widen. 2002. Epstein-Barr virus reactivation after superinfection of the $+\mathrm{BJAB}-\mathrm{B} 1$ and P3HR-1 cell lines with cytomegalovirus. BMC Microbiol. 23: 2-20.

Bergallo M., C. Costa, S. Baro, T. Musso, L. Balbo, C. Merlino and R. Cavallo. 2007. Multiplex-nested RT-PCR to evaluate latent and lytic Epstein Barr virus gene expression. J. Biotechnol. 128: 462-476. Bernasconi M., C. Berger, J.A. Sigrist, A. Bonanomi, J. Sobek, F.K. Niggli and D. Nadal. 2006. Quantitative profiling of housekeeping and Epstein-Barr virus gene transcription in Burkitt lymphoma cell lines using an oligonucleotide microarray. Virol. J. 3: 43. Coleman C.B., M.S. Nealy and S.A. Tibbetts. 2010. Immature and transitional B cells are latency reservoirs for a gammaherpesvirus. J. Virol. 84: 13045-13052.

Decausin G., V. Leclerc and T. Ooke. 1995. The lytic cycle of Epstein-Barr virus in non-producer Raji lline can be rescued by the expression of a $135 \mathrm{kDa}$ protein encoded by BALF2 ORF deleted cells. J. Virol. 69: 7309-7314.

El-Guindy A., L. Heston and G. Miller. 2010. A subset of replication proteins enhances origin recognition and lytic replication by the Epstein-Barr virus ZEBRA protein. PLoS Pathog. 6: e1001054.
Finberg R.W. and E.A. Kurt-Jones. 2004. Viruses and Toll-like receptors. Microbes Infect. 6: 1356-1360

Gargano L.M., J.C. Forrest and S.H. Speck. 2009. Signaling through Toll-like receptors induces murine gammaherpes virus 68 reactivation in vivo. J. Virol. 83: 1474-1482.

Gray D., M. Gray and T. Barr. 2007. Innate responses of B cells. Eur. J. Immunol. 37: 3304-3310.

Henault M., L.N. Lee, G.F. Evans and S.H. Zuckerman. 2005. The human Burkitt lymphoma cell line Namalwa represents a homogenous cell system characterized by high levels of Toll-like receptor 9 and activation by CpG oligonucleotides. J. Immunol. Methods. 300: 93-99.

Hopkins P.A. and S. Sriskandan. 2005. Mammalian Toll-like receptors: to immunity and beyond. Clin. Exp. Immunol. 140: 395-407.

Hummel M. and M.M. Abecassis. 2002. A model for reactivation of CMV from latency. J. Clin. Virol. 25: 123-36.

Iskra S., M. Kalla, H.J. Delecluse, W. Hammerschmidt and A. Moosmann. 2010. Toll-like receptor agonists synergistically increase proliferation and activation of B cells by Epstein-Barr virus. J. Virol. 84: 3612-3623.

Kenney SC. 2007. Reactivation and lytic replication of EBV, pp. 403-433. In: Arvin A., Campadelli-Fiume G., Mocarski E., Moore P.S., Roizman B., Whotley R. and K. Yamanishi (eds). Human Herpesviruses: Biology, Therapy, and Immunoprophylaxis. Cambridge University Press, Cambridge.

Kieff E. and A.B. Rickinson. 2007. Epstein-Barr virus and its replication, pp. 2603-2654. In: Knipe D.M., Howley P.M., D.E. Griffin, R.A. Lamb, A.M. Malcolm, B. Roizman and S.E. Straus (eds). Fields virology. Lippincott Williams and Wilkins, Philadelphia, PA.

Merat R., A. Amara, C. Lebbe, H. de The, P. Morel and A. Saib. 2002. HIV-1 infection of primary effusion lymphoma cell line triggers Kaposi's sarcoma-associated herpesvirus (KSHV) reactivation. Int. J. Cancer 97: 791-795.

Moynagh P.N. 2005. TLR signalling and activation of IRFs: revisiting old friends from the NF-kappaB pathway. Trends Immunol. 26: 469-473.

Pasare C. and R. Medzhitov. 2004. Toll-like receptors: linking innate and adaptive immunity. Microbes Infect. 6: 1382-1387.

Rickinson A.B. and E. Kieff. 2007. Epstein-Barr virus, pp. 26552700. In: Knipe D.M., Howley P.M., D.E. Griffin, R.A. Lamb, A.M. Malcolm, B. Roizman and S.E. Straus (eds). Fields virology. Lippincott Williams and Wilkins, Philadelphia, PA.

Rowe M., Kelly G.L., Bell A.I. and A.B. Rickinson. 2009. Burkitt's lymphoma: the Rosetta Stone deciphering Epstein-Barr virus biology. Semin. Cancer Biol. 19: 377-388.

Shimozuma Y., T. Ito, M. Inokuchi, M. Uchikoshi, M. Miyashit, H. Nozawa, T. Shimazaki, K. Hiroishi and M. Imawari. 2010. Reactivation of Epstein-Barr virus in B cells of patients with chronic hepatitis C. J. Med. Virol. 82: 2064-2072.

Siennicka J., A. Trzcińska, A. Częścik and M. Dunal. 2011. Tolllike receptors expression on Burkitt lymphoma cells (In Polish). Med. Dośw. Mikrobiol. 63: 349-354.

Thompson M.P. and R. Kurzrock. 2004. Epstein-Barr virus and cancer. Clin. Cancer Res. 10: 803-821.

Varthakavi V., P.J. Browning and P. Spearman. 1999. Human immunodeficiency virus replication in a primary effusion lymphoma cell line stimulates lytic-phase replication of Kaposi's sarcoma-associated herpesvirus. J. Virol. 73: 10329-10338.

Vogl B.A., U. Fagin, L. Nerbas, P. Schlenke, P. Lamprech and W.J. Jabs. 2012. Longitudinal analysis of frequency and reactivity of Epstein-Barr virus-specific T lymphocytes and their association with intermittent viral reactivation. J. Med. Virol. 84: 119-131. 